\title{
O IMPÉRIO NORTE-AMERICANO EM PERSPECTIVA: DO CENÁRIO PÓS-II GUERRA À CHINA DO SÉCULO XXI
}

\author{
THE AMERICAN EMPIRE IN PERSPECTIVE: FROM THE POST-II WORLD WAR II TO THE \\ 21ST CENTURY
}

Wallace da Silva Mello'

\begin{abstract}
Resumo
O texto que se segue é uma revisão bibliográfica sobre a formação dos Estados Unidos como poder global no pós-II Guerra Mundial e sua hipotética perda de poder para a China. Para realizar o intento, fez-se uma revisão bibliográfica sobre os EUA e as disputas sociais e políticas internas após a II Guerra Mundial das quais resultou a constituição do arranjo de poder americano no início do século XXI. Os objetivos do trabalho são: elaborar uma leitura das obras recentes sobre o poder americano; compreender as disputas sociais internas e os modelos produtivos originados desse cenário que configuraram o cenário dos EUA no século XX; analisar o potencial de crítica e questionamento da ordem social e econômica vigente proposta pela China, a partir de algumas obras de Relações Internacionais e Ciências Sociais. A metodologia utilizada foi a revisão bibliográfica básica e os resultados apontam para uma relativa complexidade nas relações políticas, sociais, científicas e culturais que tornam difíceis a afirmação do fim do Império Americano. $O$ argumento apresentado se fundamenta na discussão do modelo sócio-econômico desenvolvidos pelos EUA no pós-ll Guerra que, apesar das transformações, continua funcionando ponto central das relações internacionais e capitalistas. Embora haja uma reconfiguração do sistema global, acredita-se que os EUA ainda exercerão liderança e muito poder em várias áreas, apesar de a China constituir-se em um ator cada vez mais relevante globalmente.
\end{abstract}

Palavras-Chave: EUA; Poder Global; Império; Capitalismo; China

\begin{abstract}
The following text is a literature review of the formation of the United States as a global power in post-World War II and its hypothetical loss of power to China. In order to carry out the attempt, a bibliographical revision was made on the USA and the internal social and political disputes after World War II, which resulted in the constitution of the American power arrangement at the beginning of the 21 st century. The objectives of the work are: to elaborate a reading of the recent works on American power; understand the internal social disputes and the productive models originated from this scenario that shaped the US scenario in the twentieth century; to analyze the potential of criticism and questioning of the current social and economic order proposed by China, based on some works of International Relations and Social Sciences. The methodology used was the basic bibliographic review and the results point to a relative complexity in the political, social, scientific and cultural relations that make difficult the affirmation of the end of the American Empire. The argument presented is based on the discussion of the socio-economic model developed by the United States in the post-Second World War, which, despite transformations, continues to function as the focal point of international and capitalist relations. While there is a reconfiguration of the global system, it is believed that
\end{abstract}

\footnotetext{
${ }^{1}$ Mestre em Sociologia Política pela Universidade Estadual Norte Fluminense Darcy Ribeiro (UENF), graduado em História pelo Centro Universitário São José de Itaperuna (UNIFSJ) e Professor da Rede Estadual de Educação no Rio de Janeiro (SEEDUC-Rio). Email: wallace_sm89@hotmail.com. Agradeço aos pareceristas anônimos pelas críticas e sugestões. Os equívocos e limites do trabalho são todos de responsabilidade do autor.
} 
the US will still exercise leadership and power in a number of areas, even though China is an increasingly relevant player globallyKey-Words: USA; Global Power; Empire; Capitalism; China

Keywords: USA; Global Power; Empire; Capitalism; China

\section{INTRODUÇÃO}

Os Estados Unidos enquanto país se formou no contexto do século XIX a partir de lutas e disputas em diversas áreas. Sobretudo, a questão da escravidão ganhou no século XIX grande importância. Formado a partir da união de treze colônias com autonomia política, econômica e diferenças sociais marcantes, os EUA desde sua formação teve como uma das características fundamentais a disputa pelos rumos da organização política e social. Foi sobretudo no século XX que esse país adquiriu uma grande proeminência política, econômica, cultural, científica e simbólica. Portanto, falar em Estados Unidos é, ao mesmo tempo, falar sobre a construção e manutenção do poder deste país ao longo do século XX e suas implicações no relacionamento dos países ao redor do globo.

Após a crise da União Soviética nos anos 1980, assistiu-se a uma profusão de trabalhos sobre os Estados Unidos com características distintas, mas que de alguma forma se conectam: de um lado, os trabalhos que discutiam a questão do fim da Guerra Fria e da supremacia do modelo de sociedade liberal e democrático, tendo nos EUA um grande representante (FUKUYAMA, 1992). Ao lado deste pensamento, mas sem negar o poder americano, um outro conjunto de trabalhos tem discutido os limites do poder norte-americano, deixando claro sua objeção a esta análise e propondo uma interpretação do sistema internacional como composto não somente por uma super potência como os EUA, mas também por outros poderes que juntos tem buscado modificar o sistema internacional, o capitalismo e a relação entre e dentro dos Estados (BUZAN, WEAVER, 2004).

O sistema internacional atualmente é formado por uma estrutura hegemônica, na qual o modelo proposto e implantado pelos EUA conseguiu se sobrepor sobre os demais, inclusive superando outras propostas como o socialismo soviético e até mesmo o comunismo chinês (ARRIGHI, 2008). Outros, todavia, creem ser a China, e os outros países que formam o bloco das potências emergentes (ou regionais) um grupo alternativo que está transformando o sistema mundial (AMSDEN, 2009). Dentro deste modelo de economia e de política internacional, um dos aspectos mais importantes é o papel exercido pelas Forças Armadas e pelos sistemas de Defesa e Segurança. A política belicista norte-americana é tema de muitos debates e discussões sobre o real poder de decisão, por exemplo, de organismos como a ONU - mais especificamente o Conselho de Segurança (PEREIRA, 2013). Ainda dentro deste panorama inicial, um dos pontos mais importantes é a capacidade de inovação que o modelo econômico norte-americano foi capaz de desenvolver.

Dado este pano de fundo, o que se busca neste texto é: primeiro, uma breve apresentação e discussão sobre a formação da hegemonia dos EUA ao longo do século XX; em segundo lugar, buscar-se-á fazer uma discussão conceitual à luz do trabalho de Gramsci (2001) envolvendo os 
conceitos de americanismo e fordismo. Ao mesmo tempo, propõem-se algumas considerações sobre o conceito de império. Para isso, serão utilizadas as obras de Harvey (2004) e de Negri e Hardt (2000). Como última parte do trabalho, será discutida a importância dos temas militares na formação do império norte-americano. Para isso, utilizar-se-á o referencial proposto, sobretudo, por Michael Mann (2012) (2013). O pressuposto básico deste texto é a existência de um modelo de produção e de acumulação novos, que a partir dos EUA se espalhou por outros lugares do globo. A hipótese que se lança é a de que os EUA desenvolveram este novo modelo de produção e acumulação que, ao mesmo tempo em que era constituído, contribuiu para a consolidação do poder dos EUA. Como um exemplo desse processo de expansão deste modelo, apresenta-se o caso Chinês, a partir dos trabalhos de Nolan (2009), Hung (2011) e Ong (2006), que longe de ser uma alternativa diferente, se constitui em mais um elemento do atual estado geopolítico e geoeconômico, onde o poder dos EUA ainda é superior a todos os outros países.

\section{OS EUA E A CONSTITUIÇÃO DO PODER GLOBAL: NOTAS CONCEITUAIS}

Dado que o tema deste trabalho é Império e poder, torna-se necessário alguns comentários, ainda que superficiais - dado toda a complexidade do assunto - sobre estes conceitos. Quando se fala no poder norte-americano, um dos primeiros pontos a serem considerados é a questão da projeção internacional do modelo de sociedade dos EUA. Isso implica numa análise que considere a formação de uma nova forma de acumulação e de produção do capital, mas, ao mesmo tempo, tem reflexos na vida cotidiana, política e cultural dos países. O que se quer dizer é que uma discussão sobre os EUA no século XX e XXI passa, obrigatoriamente, por uma análise conceitual sobre o modelo de sociedade por eles construída e também difundida pelo globo.

Um dos trabalhos mais importantes sobre a nova fase do capitalismo no século XX e os EUA foi o de Gramsci (2001), "Americanismo e Fordismo". Neste texto, Gramsci discute dois componentes importantes para a identificação do modelo de sociedade nos EUA. De um lado o americanismo, com suas diferenças e especificidades em relação à Europa, e de outro o fordismo, que assinala uma marca indelével na configuração das relações de trabalho, sociais, familiares, sexuais e que, por fim, acaba por doutrinar um novo tipo de trabalhador a um novo modelo de produção e de acumulação. Partindo de uma análise comparada com países europeus, Gramsci chama a atenção para o fato de ter havido nos EUA uma formação cultural, política, econômica e religiosa diferentes, refletindo-se numa disciplina sócio-econômica também diferente. Segundo Gramsci:

Pode-se dizer, de modo genérico, que o americanismo e o fordismo resultam da necessidade imanente de chegar à organização de uma economia programática e que os diversos problemas examinados deveriam ser os elos da cadeia que marcam precisamente a passagem do velho individualismo econômico para a economia programática: estes problemas nascem das várias formas de resistência que o processo de desenvolvimento encontra em sua evolução (GRAMSCI, 2001, p. 241). 
Como o autor faz questão de reiterar, esse processo é uma evolução do modelo de acumulação anterior e que surge como uma resposta às transformações que se apresentaram na primeira metade do século XX. Obviamente, o autor não tinha total conhecimento dos acontecimentos ocorridos na segunda metade do século XX, mas via, naquele contexto - década de 1930 -, os alicerces de uma nova forma de acumulação e de produção material ${ }^{2}$. Partindo desta análise, Gramsci elenca algumas condições para a efetivação deste modelo americanista. São elas: uma racionalização da composição demográfica, controle sobre a sexualidade, um papel importante do setor financeiro e industrial, o proibicionismo e a racionalização da produção e, claro, a questão dos salários e do consumo. Todas estas ações ou posições em relação aos trabalhadores e à rotina cotidiana tem um objetivo: instrumentalizar o Estado para a execução das transformações propostas por esse novo modelo de acumulação.

Como apresentado acima, Gramsci compreende que um dos elementos fundamentais do americanismo é a questão da racionalização da composição demográfica. Isso significa um rompimento com as tradições demográficas europeias, ou seja, a eliminação de uma camada de "parasitas", como diz o autor, que não participam da vida produtiva. No dizer dele:

O americanismo, em sua forma mais completa, exige uma condição preliminar, da qual não se ocuparam os americanos que trataram destes problemas, já que na América ela existe 'naturalmente": essa condição pode ser chamada de "uma uma composição demográfica racional", que consiste no fato de que não existem classes numerosas sem uma função essencial no mundo produtivo, isto é, classes absolutamente parasitárias. (GRAMSCI, 2001, p. 243).

Um segundo elemento importante no trabalho de Gramsci e que pode ser útil para pensarmos o processo de acumulação na atual fase da modernidade é o controle sexual. Atrelado a ele também temos o proibicionismo e a racionalização da produção. Como parte fundamental do processo de controle, a dominação dos corpos, dos comportamentos e do próprio instinto sexual é parte importantíssima. Segundo o autor, "A verdade é que não se pode desenvolver o novo tipo de homem exigido pela racionalização da produção e do trabalho enquanto o instinto sexual não for adequadamente regulamentado, não for também racionalizado" (GRAMSCI, 2001, p. 252).

Por fim, um outro elemento fundamental neste processo de constituição e afirmação de um novo modelo de sociedade é a questão salarial e também de racionalização da produção. De acordo com Gramsci:

$\mathrm{Na}$ América, a racionalização do trabalho e o proibicionismo estão indubitavelmente ligados: as investigações dos industriais sobre a vida íntima dos operários, os serviços de inspeção criados por algumas empresas para controlar a 'moralidade' dos operários são necessidades dos novo método de trabalho. Quem ironizasse estas iniciativas (mesmo fracassadas) e visse nelas apenas uma

\footnotetext{
${ }^{2}$ Gramsci diz em seu texto que "Na América, a racionalização determinou a necessidade de elaborar um novo tipo de humano, adequado ao novo tipo de trabalho e de processo produtivo: esta elaboração está até agora na fase inicial, e, por isso, (aparentemente) idílica. É ainda a fase da adaptação psicofísica à nova estrutura industrial [...]" (GRAMSCI, 2001, p. 248). O interessante é perceber como ele já estava percebendo esta nova estrutura de trabalho e de acumulação, mesmo que não pudesse dar conta de todas as suas especificidades, haja vista o caráter incipiente do processo.
} 
manifestação hipócrita do puritanismo estaria negando qualquer possibilidade de compreender a importância, o significado e o alcance objetivo do fenômeno americano, que é também o maior esforço coletivo até agora realizado par criar, com rapidez inaudita e com uma consciência do objetivo jamais visto na história, um novo tipo de trabalhador e de homem (GRAMSCI, 2001, p. 266).

Esta racionalização do trabalho para a criação de um novo tipo de trabalhador e de homem não pode ser efetivada somente com medidas de coerção. É necessário a combinação de autodisciplina e também de persuasão. O que se tem, nesse caso, é um padrão de altos salários, "isto é, a possibilidade de realizar o padrão de vida adequado aos novos modos de produção e de trabalho, que exigem um particular dispêndio de energias musculares e nervosas" (GRAMSCl, 2001, p. 275).

Como se viu, Gramsci oferece em seu texto "Americanismo e Fordismo" elementos para se interpretar a fase atual da modernidade. Através de um processo de disciplinamento do trabalhador e de modificações no modelo de acumulação e circulação de capital, os estadunidenses criaram um novo modelo de sociedade, que, a partir de sua projeção internacional no pós-ll Guerra foi aos poucos sendo implantado em outros lugares do mundo. Em sentido semelhante, Domingues argumenta:

Uma segunda conclusão é a de que seu poder externo se calca em sua própria estruturação interna, na definição de uma forma civilizacional que se projeta para fora, em grande medida com fundamentos culturais, porém também vinculada a padrões econômicos de acumulação e de classe, bem como conjugada às dimensões militares, políticas e jurídicas do poder (DOMINGUES, 2014, p. 172).

A questão que se coloca é que a constituição do poder global dos Estados Unidos não está pautada apenas na dimensão militar e da força, aquilo que Joseph Nye chamou de Hard Power (NYE, 2011), mas numa construção muito mais complexa e fluida porque se vale de dimensões culturais e jurídicas para se assentar. A própria (re)definição das "regras do jogo" internacional é que está sendo constituída durante o processo de ascensão dos EUA como global player. E nesse processo a formação deste modelo fordista e americanista é fundamental, na medida em que outras formas de vida, convivência, trabalho, associação e consumo são alteradas ou eliminadas. A legitimidade deste modelo específico se torna em instrumento fundamental de política tanto interna quanto externa.

Outro conceito fundamental para o entendimento dos EUA no século XX e XXI é o de Império. Entre outros autores, David Harvey (2004) e Hardt e Negri (2000) apresentam interessantes análises que nos ajudam a entender a formação do império norte-americano. Harvey compreende o processo de formação desse Império como sendo um processo constituído pelo capitalismo e no capitalismo. Ou seja, falar em Império americano é falar do tipo de capitalismo praticado e fomentado em outros lugares pelos norte-americanos. Ao mesmo tempo, há um componente menos histórico e econômico e mais político que é a questão territorial. Na verdade, o que se quer dizer é que o imperialismo norte-americano é capitalista e territorialista. Ou seja, estas duas lógicas andam juntas. Segundo Harvey:

Creo que podemos avanzar um Bueno trecho hacia el establecimiento de um sólido marco interpretativo para las distintas formas capitalistas de imperialismo 
recurriendo a una doble dialectica, en primer lugar entre las lógicas territorial y capitalista de poder $y$ en segundo lugar entre las actuaciones internas y externas Del estado capitalista. (HARVEY, 2000, p. 141)3.

Como se viu, há uma lógica na formação do imperialismo norte-americano que se baseia em duas formas diferentes de ação. Mesmo que estas lógicas sejam importantes e até complementares, não está excluída a possibilidade delas entrarem em contradição. E claro, não é somente estes elementos que são importantes para a formação e execução deste imperialismo nos EUA: os debates internos. Neste sentido, Harvey dedica atenção especial ao estudo dos lobbies internos, como grupos conservadores, de cristão e religiosos e também do grupo ligado aos assuntos militares. Atenção especial é dada também aos temas ligados ao petróleo. Este, inclusive, é um dos temas mais importantes na construção que Harvey faz sobre a formação do império norte-americano. O mais importante aqui, é a construção teórica que Harvey faz do imperialismo norte-americano pautado tanto em questões econômicas e capitalistas, quanto em questões territoriais e políticas. Além disso, é importante reconhecer a importância dos debates internos dentro dos EUA.

Importante contribuição ao estudo do tema, Toni Negri e Michael Hardt são autores que também se dedicaram a pensar a questão do Império e do poder americano. Em seu livro "Império" de 2001, eles construíram um arcabouço um pouco diferente de Harvey. A tese do império está fundamentada numa concepção de política dialética, onde existem os que dominam e os que são dominados. Na concepção destes autores existem forças que se constituem no paradigma da soberania e do poder, e forças que resistem. Respectivamente, o Império e a Multidão. O interessante é que esta concepção de Império utiliza o consenso como um elemento de dominação. Partindo da tradição da Teoria Crítica dos estudos filosóficos e sociológicos, a dimensão do consenso opera através de uma série de estratégias de negociação e atração/cooptação que usam de estruturas e normas jurídicas, econômicas e culturais.

Isso é importante, pois deixa transparecer que o império não é constituído apenas com poder e força, mas também a partir de uma lógica de controle pelo consenso ${ }^{4}$. Nesta obra, o Império aparece desmaterializado, ou seja, sem um corpo definido e específico, mas sim caracterizado por um processo de instrumentalização e de governo sobre a multidão que se encontra mais abaixo na organização social e política. Nas palavras dos autores, "El nuevo paradigma es tanto sistema como jerarquia, construccion centralizada de normas y produccion extendida de legitimacion, extendido por todo el mundo. Se há configurado ab inicio como uma

\footnotetext{
3 "Acredito que podemos avançar um bom caminho rumo ao estabelecimento de um quadro interpretativo sólido para as diferentes formas capitalistas do imperialismo, recorrendo a uma dupla dialética, primeiro entre as lógicas de poder territorial e capitalista e, em segundo lugar, entre as ações internas e externas do estado capitalista" [Tradução do autor]

${ }^{4}$ Interessante é pensar este elemento como uma inversão do pensamento de Habermas sobre a ação discursiva. Ver HABERMAS, Jurgen. Teoria do Agir Comunicativo. São Paulo: Martins Fontes, 2012.
} 
estructura sistémica flexible y dinâmica, aticulada horizontalmente.5" (NEGRI; HARDT, 2001, p. 18).

Por fim, há um quarto elemento importante para um delineamento mínimo do conceito de império que se quer apresentar aqui neste texto e é em Mann (2012) que vamos encontrar este ponto. Ainda que de modo bem sucinto, em seu terceiro volume Michael Mann apresenta seu conceito de império deste modo:

I define an empire as a centralized, hierarchical system of rule acquired and maintained by coercion through which a core territory dominates peripheral territories, serves as the intermediary for their main interactions, and channels resources from and between the peripheries 6 . (MANN, 2012, p. 17).

Após apresentar este conceito de império, Mann distingue ainda modelos de "tipos ideais" que se observam de impérios: império direto, império indireto, império informal - este se subdivide em império informal de canhoneira, imperialismo econômico e império através de proxies (ou por procuração quando, por exemplo, um ator $X$ age em função de interesses de outro ator - $Y$ - em questão). O quarto tipo ideal é o de hegemonia. Buscando em Gramsci, Mann defende que este conceito de hegemonia vai além do Soft Power de Joseph Nye (2011), envolvendo não somente os aspectos ideológicos, mas também políticos, econômicos e militares. Nas palavras de Mann, "Because these are ideal types, no actual empire fits neatly within any one of them. Indeed, empires typically combine several of these forms of domination"” (MANN, 2012, p. 20).

Utilizando, portanto, a concepção de Mann, ou seja a partir do trabalho de Negri e Hardt ou mesmo do trabalho de Harvey, o que pode ser percebido nesta breve apresentação é uma concepção que compreende as transformações ocorridas no século XX e a formação de um poder diferente aos EUA a partir de uma série de estratégias e de situações que, envolvendo uma série de ações - militares, políticas, econômicas e culturais -, acabaram por colocar na ordem do dia um novo padrão de sociedade, de acumulação e de produção a partir da experiência dos EUA. Esse novo padrão é o que Gramsci chamou de americanismo e fordismo, pautado num processo de 'domesticação' do trabalhador - ao criá-lo como um novo ser - e também nos altos salários e no consumo.

No próximo item será explorado a questão da formação do poder americano no século XX, especialmente a questão do poder econômico e do modelo de acumulação. Atenção especial será dada também aos debates internos nos EUA. Para tanto, os trabalhos de Mann (2011) (2012) serão as bases do texto.

\footnotetext{
5 "O novo paradigma é o sistema e a hierarquia, a construção centralizada de normas e a produção ampliada de legitimidade, espalhadas pelo mundo. Foi configurada a desde o início como uma estrutura sistêmica flexível e dinâmica, injetada horizontalmente". [Tradução do autor]

6 "Eu defino um império como um sistema hierárquico centralizado de domínio adquirido e mantido por coerção através do qual um território central domina territórios periféricos, que servem como intermediários para suas principais interações e canaliza recursos de e entre as periferias." [Tradução do autor]

7 "Como são tipos ideais, nenhum império cabe (ou coube) perfeitamente dentro de um deles (dos tipos ideais. Na verdade, impérios normalmente combinam alguns dessas formas de dominação". [Tradução do autor]
} 


\section{O IMPÉRIO NORTE-AMERICANO: NOTAS HISTÓRICAS}

Para o entendimento da formação do poder norte-americano é necessário o entendimento de que não somente o fordismo foi fundamental para a execução deste projeto, mas também de que o keynesianismo e o welfare state foram muito importantes também. Estes três elementos juntos criaram condições internas e motivações externas para a formação do poder norteamericano. Obviamente, esse processo não foi simples, pelo contrário, muitas lutas e disputas existiram no centro do debate.

Foi na segunda metade do século XX que os americanos constituíram, de fato, seu poderio político, econômico e militar ao redor do globo. Neste processo, especial atenção teve a Europa, o Plano Marshall e o welfare state europeu. Até porque, o contexto de ameaça do comunismo tornava a Europa um terreno de importância estratégica para os EUA. No plano interno, o que se tem é uma luta desde antes da guerra pela definição do modelo de produção, de relação patrãoempregado, e de consumo que se teria. Mann (2012) apresenta, a partir de uma comparação entre os movimentos dos trabalhadores nos EUA e em outros lugares do globo, como nos EUA estes movimentos sofreram com duros golpes, o que, por sua vez, os tornou mais fracos. São eles: o poder militar superior; o emprego da violência e a legitimidade pela lei; o isolamento os sindicatos em comparação com os países europeus; e a divisão dos sindicatos nos EUA a partir da raça, etnia e religião - algo também excepcional segundo Mann (2012). Além disso, Mann também aponta a questão do crescimento econômico dos EUA - que tornaria os trabalhadores de lá 'mais felizes' -; a questão da democracia branca até a metade do século XX; a questão da divisão regional dos partidos, diferente dos casos da Inglaterra, Nova Zelândia e da Austrália.

Além disso, há alguns estudiosos que apontam a questão das instituições nos EUA como elementos importantes para explicar isso. Além destes pontos, Mann discute a questão dos direitos das mulheres e do incentivo à educação como elementos que configuraram uma estrutura social diferente nos EUA do entreguerras. De todo modo, o que Mann deixa muito claro nesta parte de seu texto é que os EUA estavam caminhando rumo ao capitalismo, ou à implementação de mudanças capitalistas. Ao mesmo tempo, um grande grupo, um bloco político ligado aos sindicatos, foi sendo mitigado por políticas e contingências históricas que tornavam os EUA bem diferentes dos países europeus ou mesmo de língua inglesa. Mesmo quando houve movimentos mais à esquerda, como no contexto do New Deal, Mann deixa claro sua visão de que este processo, longe de ter sido conclusivo, foi um momento de modificações complexas, mas ao mesmo tempo imperfeitas.

No contexto da II Guerra as modificações e medidas capitalistas pautadas nos preceitos liberais ganharam força nos EUA. Tanto é verdade que Mann observa "War produces big-state conservatism, not leftish but led by business corporations and the military"8 (MANN, 2013, p. 39). E este é um elemento novo: não somente medidas econômicas e políticas que favoreceram o

\footnotetext{
${ }^{8}$ A guerra produz um conservadorismo estatal, não esquerdista, mas liderado por corporações empresariais e militares". [Tradução do autor]
} 
processo de giro à direita em favor de medidas capitalistas, mas também a importância do setor militar nas discussões internas nos EUA. É importante dar atenção a um outro processo que se desenvolveu no contexto da II Guerra e depois dela que foi a luta contra o comunismo. Esta ideologia foi fundamental para também diluir ainda mais a luta da esquerda nos EUA.

Seja no âmbito cotidiano, ou nos meios acadêmicos passando pelos debates políticos e públicos, a ideologia anticomunista foi fundamental para embasar toda uma política belicista dos EUA no contexto da Guerra Fria. Mann (2013, p. 54-55) lembra que termos e frases anticomunistas que exaltavam a morte dos "commies" eram comuns à época. Segundo ele, "Cold war anticommunism was a powerful ideology, one that was immanent in the sense that it reinforced the cohesion and sense of solidarity of the nation - and the same true the other side of the Curtain" (MANN, 2013, p. 55). Todos estes elementos formam um panorama que permite que se chegue à conclusão de que os EUA de meados da segunda metade do século XX já é de longe um dos países mais capitalistas do mundo. Mesmo incorporando diversos grupos sociais - como no movimentos dos Direitos Civis - ou mesmo reduzindo a desigualdade o giro à direita foi considerável.

Como se disse acima, os temas militares exerceram um forte poder dentro da política dos EUA no pós II Guerra. Segundo Mann (2013), ao mesmo tempo havia o chamado 'Keynesianismo Comercial' e o 'complexo militar industrial'. Estes dois elementos contribuíram para a constituição de um regime de crescimento econômico, utilizando a combinação de forças de mercado, planejamento de governo e juros progressivos, criando um novo tipo de consumidor ${ }^{10}$ (MANN, 2013, p.46). Além do poder político, que no contexto da Guerra Fria o grupo ligado aos temas militares conseguiram, um outro tema importante é a consequência da política de apoio e incentivo ao desenvolvimento tecnológico militar. Como diz Mann, "Military R\&D produced civilian spin-offs, like computers and semiconductors. This was less commercial than military Keynesianism, less economic policy than the unintended consequences of global military power"11 (2013, p. 47). Durante as décadas de 1950 e 1960 esse grupo conseguiu altos ganhos econômicos com o desenvolvimento tecnológico e científico. Esse elemento é mais um importante ponto na formação de um bloco - não necessariamente homogêneo - que contribuiu fortemente para o fracasso dos programas mais à esquerda nos EUA e reforçaram o sentimento anticomunista e conservador na política americana.

Sobre isso, vale recorrer ao trabalho de Larry Bartels sobre a democracia americana. Publicado em 2008, Unequal Democracy é uma resposta ao trabalho de Robert Dahl "Who

\footnotetext{
9 "O anticomunismo na Guerra Fria era uma ideologia poderosa, imanente no sentido de que reforçava a coesão e o senso de solidariedade da nação - e o mesmo vale para o outro lado da Cortina [de Ferro]. [Tradução do autor]

${ }^{10}$ Atenção ao termo utilizado por Mann para retratar as transformações que ocorreram na economia dos EUA com a implantação do chamado Keynesianismo comercial (ou poderíamos utilizar o termo fordismo?) e com a força adquirida pelo Complexo-Industrial Militar, pois acredita-se haver uma relação possível entre estes termos e a obra de Gramsci "Americanismo e Fordismo".

11 "A pesquisa e o desenvolvimento tecnológico no setor militar trouxe desdobramentos civis, tais como computadores e semicondutores. Isso foi menos comercial do que o keynesianismo militar, menos política econômica do que as conseqüências não intencionais do poder militar global"
} 
Governs?", publicado nos anos 1950. Nesta obra, Dahl, a partir da análise de caso da cidade de New Heaven, chegou à conclusão de que ainda que existissem diferenças econômicas consideráveis. O pluralismo dos grupos sociais envolvidos e as coalizões formadas acabavam por dispersar o poder e contrabalançar os poderes maiores. Resultado: havia de fato uma democracia pluralista nos EUA haja vista o número de grupos diferentes e de diversos matizes ideológicos. Tomando isso, e outros trabalhos, Bartels (2008) faz uma análise da democracia norte-americana tentando mostrar que, na verdade, a democracia dos EUA não é tão igual assim. A partir de uma intensa utilização de métodos quantitativos conclui-se que houve um intenso processo de aumento da desigualdade nos EUA. Analisando as eleições e os dados de crescimento econômico e também de distribuição de renda, Bartels (2008) conclui que em determinados governos o crescimento e distribuição da renda se dá ao longo do mandato, ao passo que os governos conservadores criam mecanismos que permitem um crescimento maior nos estratos mais elevados da sociedade americana.

Como então os governos conservadores conseguem se eleger? A resposta é que haveria uma "miopia eleitoral", causada pelo fato de que o crescimento econômico e a distribuição são mais sentidas no segundo mandato dos governos democratas e diminuem ao longo do mandato ao passo que os governos republicanos conseguem segurar a economia e fazê-la crescer no ano eleitoral, causando uma falsa sensação de ganhos econômicos nas classes mais pobres dos cidadãos americanos (BARTELS, 2008). Novamente, este é mais um elemento a compor o panorama de fortalecimento de uma aliança conservadora, liberal - ou neoliberal em tempos mais recentes - nos EUA, que permitiu uma maior projeção interna e, ao mesmo tempo, externa do padrão de acumulação baseado no consumo.

Ao lado desta política interna de fortes disputas e da vitória do modelo conservador de política econômica e social, os americanos conseguiram com suas relações políticas e diplomáticas estabelecer um domínio praticamente completo sobre o Ocidente e partes da Ásia. Sobretudo no contexto da Guerra Fria, os americanos projetaram uma política baseada na assistência e consulta aos aliados ocidentais. Segundo Mann:

The European nation-states remained allies. U.S. presidents often consulted their leades and American empire was invisible to most Europeans. Ikenberry (2001, chap. 6) notes that to maintain American dominance, revitalize the world economy, and contain the communist bloc, Europe, Japan and the Unites States were bound together in an open, multilateral economic order. Potential conflicts among the allies were 'captured and domesticated in an iron cage of multilateral rules, standards, safeguards, and disputes resolutions procedures ${ }^{12}$ (MANN, 2013, p. 90).

Ao redor do mundo o que se observou a partir da segunda metade do século XX foi uma forte política de dominação e de exercício do poder norte-americano. Utilizando diferentes

\footnotetext{
12 "Os estados-nação europeus permaneceram aliados. Os presidentes dos EUA muitas vezes consultavam seus líderes e o império americano era invisível para a maioria dos europeus. Ikenberry (2001, cap. 6) observa que, para manter o domínio americano, revitalizar a economia mundial e conter o bloco comunista, a Europa, o Japão e os Estados Unidos estavam unidos em uma ordem econômica multilateral aberta. Conflitos potenciais entre os aliados foram "capturados e domesticados em uma gaiola de ferro de regras multilaterais, normas, salvaguardas e disputas de procedimentos de resolução" [Tradução do autor]
} 
estratégias, ou nos termos propostos por Michael Mann (2012), se valendo de várias práticas 'tipos ideais' do império, observou-se a projeção do poder americano e o controle cada vez maior de áreas de influência.

In the West American Power was not imperial but hegemonic accepted by countries bound together in a dense network of institutions under U.S. leadership, prospering mainly through their own efforts, though assisted by economic interdependence and mutual defense led by United States. [...] Finally, imperialism in the Middle East remained unfinished business. The region suffered in terms of both economic and democratic development from the curse of oil, while interstate conflict and the worsened Israeli-Palestinian conflict compromised American policy. (MANN, 2013, p. 126).

Após o final da década de 1980 a situação ficou mais favorável ainda aos EUA pois, com o processo que vinha se desenvolvendo desde os anos 1970 de reforma do capitalismo com medidas ainda mais à direita e mais liberais, o modelo de desenvolvimento, de acumulação e de produção do capital se intensificou e ganhou uma nova dinâmica: a revolução tecnológica que varreu o mundo. O processo que havia transcorrido no século XX com o poderio militar, econômico e político dos EUA sendo aumentado tomou proporções ainda maiores com a liderança tecnológica dos mesmos. O setor de inovação e de desenvolvimento de softwares ganhou grande importância no mercado globalizado. E, como era de se esperar, os americanos conseguiram manter o controle do desenvolvimento das mais avançadas tecnologias. O predomínio do Império sobre a multidão ganhou novos contornos ao final do século XX.

Antes de falar especificamente sobre o ponto acima mencionado da questão do complexo militar e da importância dele na formação do poder norte-americano, faz-se necessário alguns comentários sobre as teses que apontam um reordenamento do sistema internacional, com indícios de possíveis substitutos à potência hegemônica - os EUA. Para tanto, serão utilizados os trabalhos de Nolan (2009), Hung (2011) e de Aiwah Ong (2006).

\section{O IMPÉRIO NORTE-AMERICANO: A PROJEÇÃO DO MODELO DE ACUMULAÇÃO FLEXÍVEL}

Muito se disse ao final da Guerra Fria sobre a possibilidade real de configuração do sistema internacional com uma ordem unipolar. Neste contexto, os EUA exerciam um poder nunca antes visto devido a sua capacidade política, econômica, simbólica, cultural e militar. Tanto na lógica do capital quanto na lógica territorial, os EUA eram apontados como o grande modelo segundo o qual as sociedades se moveriam. Tão logo percebeu-se não ser essa a realidade, especialistas começaram a lançar questões sobre quem poderia representar uma ameaça, e talvez mesmo substituir o poderio norte-americano.

O padrão de produção e de acumulação baseado num novo tipo de trabalhador e de homem, que Gramsci já apresentava, e nos mecanismos de projeção que tanto Harvey quanto Negri e Hardt - poder econômico, político, simbólico e militar - acabaram por trazer para a gravidade norte-americana os países mais importantes. Um dos exemplos é a China. Apontada 
por alguns como o país que teria o poder de rivalizar com os EUA (ARRIGHI, 2007). Neste sentido, o que se observou foi um processo de transmissão de valores e normas políticas e econômicas para outros lugares do mundo. Aquele modelo apresentado algumas páginas acima de acumulação e de produção de um novo tipo de trabalhador para uma nova sociedade havia alcançado seu momento de transbordamento dentro dos EUA e acabou por se espraiar por outros territórios.

Sobre isso é importante o trabalho de Aihwa Ong "Neoliberalism as Exception" de 2006. Neste trabalho a autora busca mostrar como que no período recente na Ásia, especialmente na China, o modelo de capitalismo americano implantado foi amplamente difundido, tornando-se a fonte de inspiração do modelo de organização política e econômica daqueles lugares. Neste sentido, o neoliberalismo se tornou tão hegemônico que em diversas regiões pode-se pensar em "exceções ao neoliberalismo". Nestas regiões, a autora explica as relações de trabalho e as ações do governo chinês e de outros como sendo regidas pela ótica da 'cidadania graduada'. Utilizando o pensamento de Foucault sobre poder moderno, a autora quer mostrar que existem áreas onde há mais espaço para a cidadania e áreas onde estes 'privilégios' não devem ser concedidos se quer efetivamente desenvolver tal região. Haveria algo como uma soberania sobreposta, ou seja, agências que disputam o controle soberano, governo, mercado, terceiro setor.

I thus use the term graduated sovereignty to refer to the effects of a flexible management of sovereignty, as governments adjust political space to the dictates of global capital, giving corporations na indirect Power over the political conditions of citizens in zones that are differently articulated to global production and financial circuits. [..] In short, 'graduated sovereignty' is na effect of states moving administrators of a watertight national entity to regulators of diverse spaces and populations that link with global markets ${ }^{13}$. (ONG, 2006, p. 78).

É perceptível, sob esta ótica, o processo de expansão de uma lógica mercadológica, capitalista e ocidental sobre a Ásia. As reformas neoliberais iniciadas nos EUA e Inglaterra no final da década de 1970, e nas décadas de 1980 e 1990, acabaram por atingir novos 'ecossistemas' globais que são integrados ao mercado capitalista globalizado. Além disso, eles passam a serem controlados por lógicas, mecanismos também neoliberais e capitalistas. Nas chamadas 'áreas marrons' a cidadania, os direitos básicos, de trabalho, condições de vida e de oportunidades são mitigados pelos interesses do mercado. Mas ao contrário do que se poderia pensar, o Estado não é um agente que se encontra fora deste processo. Ele está junto, ganha junto com isso, com investimento e a entrada cada vez mais intensa de empresas internacionais em seu território.

Utilizando o referencial de Negri e Hardt, o Império se expandiu sobre outras Multidões ou sobre outra parte da Multidão - difundindo não apenas valores políticos e econômicos, mas também normas educacionais e uma normatização do trabalho diferentes do que até então era

\footnotetext{
13 "Assim, uso o termo soberania graduada para me referir aos efeitos de uma gestão flexível da soberania, à medida que os governos ajustam o espaço político aos ditames do capital global, dando às corporações um poder indireto sobre as condições políticas dos cidadãos em zonas que são diferentemente articuladas ao global circuitos de produção e financeiros. [..] Em suma, a "soberania graduada" é um efeito dos Estados que movem os administradores de uma entidade nacional impermeável para os reguladores de diversos espaços e populações que se conectam com os mercados globais."
} 
praticado. O processo que Gramsci viu na década de 1920 e 1930 está, seguindo a interpretação de Ong (2006) $)^{14}$, consolidado também em regiões da Ásia, sobretudo na China que apontada como a possível potência rival dos EUA, demonstrou-se, nesta interpretação, ser mais uma extensão do que uma opção ao poder de Império dos EUA.

Outro trabalho importante para a configuração deste panorama do poder norte-americano é o trabalho de Hung (2011) intitulado "O Braço Direito dos EUA?". Neste texto, o autor constrói um argumento pautado em dados quantitativos de que os EUA não têm na China um rival, mas uma extensão de seu poder, ou Império. No início do texto Hung deixa claro seu ponto:

Neste artigo, traço as origens históricas e sociais da dependência crescente da China e do Leste Asiático em relação aos mercados de consumo do Norte Global, como fonte de seu crescimento, e aos instrumentos financeiros dos Estados Unidos, como reserva de valor de suas poupanças. Em seguida avalio as possibilidades de superação dessa dependência em longo prazo, argumentando que, para criar uma ordem econômica mais autônoma na Ásia, a China teria que transformar um modelo de crescimento orientado para as exportações - que tem beneficiado principalmente os setores de exportadores da região costeira, que o perpetuam - em um modelo impulsionado pelo consumo doméstico, por meio de uma ampla redistribuição de renda para o setor rural-agrícola. Isso não será possível, contudo, sem romper o predomínio político da elite urbana costeira. (HUNG, 2011, p. 18).

Como se viu pelo texto, o autor constrói uma ligação histórica a partir da economia, da globalização e da política entre os EUA e o Leste Asiático. Longe de ser um milagre, o crescimento desta região está ligado ao fato dos EUA terem:

(...) projetado como parte de um esforço para criar baluartes subordinados e prósperos contra o comunismo na região da Ásia e do Pacífico. Essas economias nunca se destinaram a desafiar os interesses geopolíticos e geoeconômicos americanos. Em vez disso, eram clientes subservientes que auxiliavam Washington a realizar seus planos para a região. (HUNG, 2011, p. 19).

(...) we saw China's uneven impact on the prospect of development in other developing countries. It is apparent that China has no intention of or capacity for transforming the global neoliberal order because the China boom has been relying heavily on transnational free trade and investment flow. China also makes significant contribution to the perpetuation of U.S. global dominance through its addiction to U.S. public debt. ${ }^{15}$ (HUNG, 2016, p. 169).

Através de uma série de dados estatísticos e gráficos, o autor apresenta uma contundente análise do crescimento econômico chinês, demonstrando como este se deu de fato a partir de um modelo baseado na exportação de bens para o Ocidente. Além disso, observa-se outro processo em curso de importância considerável: o aumento da desigualdade entre patrões e empregados e também o baixo nível de consumo comparado ao investimento. Estas são mais duas facetas interessantes do processo de transformação da economia chinesa. Pois, deixam claro, mais uma vez, que há um processo de transformação no modelo produtivo e de acumulação de capital em

${ }^{14}$ Esta conexão entre os autores e conceitos foi feita pelo autor deste texto.

15 "É evidente que a China não tem intenção ou capacidade de transformar a ordem global neoliberal, porque o boom da China tem dependido fortemente do livre comércio transnacional e do fluxo de investimentos. A China também faz uma contribuição significativa para a perpetuação do domínio global dos EUA através de sua dependência da dívida pública dos EUA." 
curso muito influenciado pela lógica do neoliberalismo e do Império americano. A China, ou pelo menos a parte mais costeira do país - aquela que recebeu mais investimento e que incorporou parte da população chinesa formando uma classe média que consome - é um exemplo interessante deste processo em curso de expansão do modelo de acumulação flexível desenvolvido já nos EUA no século XX. Segundo Domingues:

O novo regime do capital foi chamado por outros, seguindo na mesma direção, de 'acumulação flexível', implicando o fim da produção em massa, a segmentação dos mercados, o ecletismo nas práticas laborais - isto é, mais heterogeneidade e contingência vis-à-vis o grande esforço de homogeneização que o primeiro regime impôs. (DOMINGUES, 2013, p. 72.).

Numa perspectiva diferente, Peter Nolan (2009) concebe o momento não como uma clara representação do poder dos EUA e de expansão do modelo de acumulação proposto e desenvolvido por aquele país, mas um momento marcado pela oposição entre dois modelos e um possível caminho de superação das fragilidades econômicas, políticas e, sobretudo, sociais do atual modelo. De fato, como diz o título, é o fim do "Wild Capitalism" que está proposto. A partir de uma série de análises, Nolan apresenta um panorama dos EUA no século XX no qual deixa claro que ao mesmo tempo em que a riqueza aumentou, com o crescimento econômico aumentou junto o número de obesos, pessoas infelizes, da violência. Segundo Nolan (2009) a cultura da arma e da resolução pela violência ganhou muita força nos EUA. Todos estes elementos são utilizados para demonstrar as contradições que o processo de desenvolvimento econômico dos EUA no século XX trouxe.

Ao lado desta perspectiva, Nolan traça uma análise sobre o relacionamento entre EUA e China onde, por questões políticas, econômicas e ambientais, não é possível a continuidade do modelo de desenvolvimento nestes moldes já apresentados. Observando os riscos à saúde pública - qualidade do ar e higiene -, os danos à agricultura - desertificação, chuva ácida e erosão dos solos - Nolan aponta para a possibilidade de superação deste modelo e dos entraves por ele apresentados a partir da cooperação entre os EUA e China. Segundo ele,

There is a possibility of serious conflict between them [China e Estados Unidos], which would be a catastrophe of humanity. Faced with such a possibility, SinoAmerican cooperation is the only rational path for the leadership of the two countries to pursue $^{16}$ (NOLAN, 2009, p. 121).

Um dos pontos de convergência que permitem que China e os Estados Unidos cooperem é o fato de que nos dois países houve desenvolvimento capitalista. $\mathrm{Na}$ China, entretanto, este desenvolvimento obedeceu a condições diferentes como, por exemplo, o fato de ter sido mais direcionado pelo Estado - na construção de obras públicas - e sob a influência do confucionismo. Ainda que este quadro possa ser apresentado, existem alguns desafios à China para efetivamente entrar na globalização, haja vista algumas contradições que ela precisa resolver (NOLAN, 2009). São elas: a questão energética na China, o debate ecológico, o aquecimento global, a pobreza e a desigualdade, além de questões econômicas e também referentes ao aparelho burocrático

16 "Há a possibilidade de um sério conflito entre eles (China e Estados Unidos), que seria uma catástrofe humana. Diante de tal possibilidade, a cooperação sino-americana é a única trajetória racional que as lideranças dos países podem buscar." 
chinês. Tudo isso deixa claro que aquele processo de desenvolvimento já apresentado, comentado e discutido neste trabalho, baseado no processo de acumulação flexível e polarizado e que se consolidou a partir dos EUA no pós II Guerra se expandiu para outros lugares do mundo, contribuindo para a transformação produtiva e das relações sociais e de trabalho ao redor do mundo.

A resposta de Nolan é sui generis, pois compreende que a cooperação entre EUA e China é o caminho possível e desejável para a superação do atual estado de coisas. Em contraposição a isso, outros autores defendem que a relação entre estes dois países, longe de representar um novo caminho político e econômico, representa a afirmação dos EUA como o grande Império nos tempos atuais. De todo modo, o que se percebe, é uma relação muito forte entre os EUA, sua política interna, suas instituições econômicas e políticas, suas práticas culturais e tradições acabaram por atingir diversos países e modificaram, de modo indelével, várias sociedades.

\section{CONCLUSÃO}

Ao longo deste texto buscou-se apresentar alguns elementos que permitissem uma interpretação do poder dos EUA, de sua formação e seu desenvolvimento no século XX. Longe de ser um esforço finalizado, esse trabalho se caracteriza por ser um esforço de compilação de diferentes trabalhos e interpretações na formação de um corpo novo, minimamente coerente que ajude a entender a natureza do poder norte-americano e as possibilidades de modificação da situação atual no mundo. Entender o poder dos EUA é fundamental se o que se pretende é propor reformas no sistema internacional, na economia global e também nos aspectos cultuais e ideológicos.

Como se viu, os EUA se constituíram como o grande poder no mundo através de um processo que envolveu aspectos militares, políticos, econômicos e culturais. Foi da formação de novo trabalhador, de um novo homem, de uma nova mulher, de uma nova família e de novas relações de trabalho que se iniciou um processo paulatino - às vezes não - de substituição dos velhos hábitos e se consolidou um novo tipo de sociedade, pautado no consumo, nos altos salários e no capitalismo.

Também se observou como esse processo se deu, não sem disputas. Ou seja, houve um grupo, um bloco dentro dos EUA, que agiu para a execução deste projeto. Políticos, industriais, militares e partidos políticos - especialmente os Conservadores, mas não somente - se articularam para a implementação deste novo modelo de sociedade e de trabalhador. Mas não parou por aí: viu-se que esse processo de transformação das relações de trabalho e também das relações sociais mudou outras sociedades, como o exemplo dado da China. Viu-se que em diversos espaços surgiram novas demandas políticas e econômicas que colocaram os cidadãos destas regiões como cidadãos de segunda classe em comparação com os interesses do governo e de corporações estrangeiras. 
Sobretudo, observou-se, a partir dos textos apresentados e da interpretação dada aos mesmos, que a China e o sistema internacional de modo geral, longe de simbolizar uma mudança estrutural ou intensa, sinaliza a manutenção do poder dos EUA e sua projeção ainda maior. Algo que não foi discutido no texto mas é possível de ser apontado são as reformas implementadas na zona do Euro recentemente. Os EUA ainda se caracterizam como o grande poder político e econômico do mundo pois, ainda que tenham surgidos novos países com maior importância BRICS, potências regionais e/ou emergentes -, o núcleo do capitalismo, a inovação, ainda se mantém nas mãos dos americanos.

Entretanto, esta análise não impede, mas pelo contrário, estimula o pensamento independente a projeção a partir de novas dinâmicas econômicas e políticas, de possibilidades de inovação e transformação dos sistemas internacionais. Reconhecer que os americanos ainda são o grande poder no mundo não deve engessar o processo de transformação político, econômico e social.

* Artigo recebido em 30 de dezembro de 2018 Aprovado em 21 de julho de 2019.

\section{REFERÊNCIAS}

AMSDEN, Alice. A Ascensão do "Resto": os desafios ao Ocidente de economias com industrialização tardia. São Paulo: Ed. Da UNESP, 2009.

ARRIGHI, Giovanni. Adam Smith em Pequim. São Paulo: Boitempo, 2008.

BARTELS, Larry. Unequal Democracy. New Jersey: Princeton University Press, 2008.

BUZAN, Barry; WEAVER, Ole. Regions and Powers. Cambridge University Press, 2004.

DOMINGUES, José Maurício. Modernidade Global e a Civilização Contemporânea. Belo Horizonte: Ed. UFMG, 2013.

DOMINGUES, José Maurício. Leituras do Império: O Poder Global dos Estados Unidos Reavaliado. Contexto Internacional - vol. 36, no 1, janeiro/junho, 2014.

FUKUYAMA, Francis. O Fim da História. Rio de janeiro: Rocco, 1992.

GRAMSCI, Antonio. Americanismo e fordismo In: Cadernos do Cárcere, vol. 4. Rio de Janeiro: Civilização Brasileira, 2001.

HARVEY, David. EI Nuevo Imperialismo. 2004.

HUNG, HO-FUNG. O Braço Direito dos Estados Unidos? Novos Estudos - CEBRAP. № 89, São Paulo, 2011.

HUNG, HO-FUNG. The China Boom: Why China will not rule the world. New York: Columbia University Press, 2016. 
MANN. Michael. The source of Social Power. Vol. 3. Cambridge: Cambridge University Press, 2012.

2013

The source of Social Power. Vol. 4, Cambridge: Cambridge University Press,

NEGRI, Toni; HARDT, Michael. Imperio. Rio de Janeiro: Editora Record, 2000.

NOLAN, Peter. Crossroads: The End of Wild Capitalism. Londres: Marshall Cavendish, 2009).

NYE. Joseph. The Future of Power. New York: PublicAffairs, 2011.

ONG, Aihwa. Neoliberalism as exception. London: Duke University Press, 2006.

PANITCH, Leo; GINDIN, Sam. The Making of Global Capitalism. Londres e Nova York: Verso, 2012.

PEREIRA, Alexsandro. A Reforma do Conselho de Segurança da ONU: Notas Preliminares. Conjuntura Global, Curitiba, Vol. 2, n.3, jul./set., 2013, p. 117-121. 